\title{
A Computer Output Microfilm Serials List for Patron Use
}

William SAFFADY: Wayne State University, Detroit, Michigan.

Library literature generally assumes that COM is better suited to staff rather than patron use applications. This paper describes a COM serials holdings list intended for patron use. The application and conversion from paper to COM are described. Emphasis is placed on the selection of an appropriate microformat and easily operable viewing equipment as conditions of success for patron use.

As a marriage of dynamic information-handling technologies, Computer Output Microfilm (COM) is a systems tool of potentially great significance to librarians. Several libraries have reported successful COM applications initiated within the last few years. The two most recent-Fischer's description of four COM-generated reports used by the Los Angeles Public Libraries and Bolef's account of a COM book catalog at the Washington University School of Medicine Library-stress the time, space, and cost savings so frequently reported in analyses of the advantages of COM.1,2 This article describes the substitution of microfilm for paper as the computer output medium in one of the most common library automation applications, a serials holdings list intended for use by library patrons. It is interesting that, at a time when librarians are insisting on the importance of patron acceptance of technological innovation, the recent literature reports COM applications intended solely for staff use. Bolef, in fact, lists staff rather than patron use among the characteristics of potentially successful library COM applications. The report that follows suggests, however, that careful attention to the selection of an appropriate microformat and viewing equipment can successfully extend the effectiveness of $\mathrm{COM}$ to include patron-use library automation applications.

\section{THE APPLICATION}

The Union List of Serials in the Wayne State University Libraries is a computer-generated alphabetical listing, by title, of serials held by the Wayne State University library system and some biomedical libraries in the Detroit metropolitan area. Sullivan describes it as "informative in purpose and conventional in method."3 As with many similar applications, serials 
holdings were automated in order to unify and disseminate hitherto separate, local records. The list is primarily a location device, giving for each title the location within the library system and information on the holdings at each location. It is updated monthly, the July 1974 issue totalling 1,431 pages. In paper form, twenty copies produced on an IBM 1403 line printer using four-ply carbon-interleaved forms were distributed for use throughout the library system.

The list shares some of the characteristics that have marked other successful COMi applications. ${ }^{4}$ It consists of many pages and has a sizeable distribution. Quick retrieval of information is essential. Use is for reference rather than reading. There is no need to annotate the list and no need for paper copies, although the latter requirement would not rule out the use of COM for this particular application. Patrons simply consult the list to determine whether the library's holdings include a particular serial and then proceed to the indicated location. It is interesting that serials holdings lists, long recognized as an excellent introductory library automation application, should also prove an excellent first application for COM.

Complexities of format and viewing equipment selection aside, the conversion of output from paper to microfilm presented no problems. Since the Wayne State University Computing and Data Processing Center does not have COM capability, the University Libraries, after careful consideration of several vendors, contracted with the Mark Larwood Company, a microfilm service bureau equipped with a Gould Beta COM 700L recorder. The Beta COM is a CRT-type COM recorder with an uppercase and lowercase character set, forms-overlay capability, proportional spacing, underlining, superscripts, subscripts, italics, and a universal camera capable of producing $16,35,70$, and $105 \mathrm{~mm}$ microformats at several reduction ratios. A decisive factor in the selection of this particular vendor was the Beta COM's dedicated PDP-8/L minicomputer that enables the COM recorder to accept an IBM 1403 print tape, thereby greatly simplifying conversion and eliminating the expense of reprogramming.

\section{MICROFORMAT SELECTION}

As Ballou notes, discussions of COM have tended to concentrate more on the computer than on micrographics, but for a patron-use COM application the selection of an appropriate microformat is of the greatest importance. ${ }^{5}$ However, there has been an unfortunate emphasis placed, both in the literature of micrographics and by vendors, on microfiche, the format now dominating the industry, especially in COM applications. Such emphasis ignores the fundamental rule of systems design, that form follows function. Each of the microformats has strengths and weaknesses that must be analyzed with reference to the application at hand. For a patron-use, COM-generated serials holdings list, ease of use with a minimum of patron film handling is a paramount consideration. Microfiche is clearly unsuitable for a list of over 1,400 pages. Even at $42 \times$ reduction, the pa- 
tron would be forced to choose from among seven fiches, each containing 208 pages. The difficulties of handling and loading, combined with library staff involvement in a program of user instruction, make fiche an unattractive choice.

Instead, the relatively large size of the holdings list suggests that one of the $16 \mathrm{~mm}$ roll formats offers the best prospects of containing present size and future growth within a single microform. The disadvantages of the conventional $16 \mathrm{~mm}$ open spool-the necessity of threading film onto a take-up reel before viewing-can be minimized by using a magazine-type film housing. The popular cartridge format eliminates much film handling, but cartridge readers are very expensive, necessitating a considerable investment where many readers are required. Even with the cartridge, it is still possible for a patron to unwind the film from the take-up reel, necessitating rethreading before viewing. Fortunately, microfilm cassettes overcome this difficulty. Unlike the cartridge format, $16 \mathrm{~mm}$ cassettes feature selfcontained supply and take-up reels. The film cannot be completely unwound from the take-up reel and the cassette can be removed from the viewer at any time without rewinding. Patron film handling is virtually eliminated. The cassette format has proven very popular with British libraries, where it has been used with satisfactory results in COM applications. ${ }^{6}$

\section{VIEWING EQUIPMENT}

Success in format choice is contingent on the selection of appropriate viewing equipment. As Larkworthy and Brown point out, the best viewer for patron-use COM applications is one that can easily be operated by the least mechanically inclined person. ${ }^{7}$ Fortunately, cassette viewers, while limited in number, tend to be very easy to operate. The viewer chosen for use with the Union List of Serials, the Memorex 1644 Autoviewer, features a simple control panel, fixed $24 \times$ reduction, easily operated focus and scan knobs, motorized film drive for high-speed searching, and a manual hand control for more precise image positioning. The screen measures eleven by fourteen inches in size, with sufficient brightness for comfortable ambient light viewing. Other cassette viewers examined, however satisfactory they might be in other respects, failed to meet the peculiar requirements of this particular application.

\section{DISCUSSION}

Since its introduction in April 1974, the COM-generated Union List of Serials in the Wayne State University Libraries has enjoyed a satisfactory reception. Patrons have learned to consult the COM list with little difficulty. The selection of an appropriate microformat and easily operated viewing equipment have kept staff involvement in patron instruction to a minimum. There appears to be no reason for limiting potential library COM applications to those used primarily or solely by staft members. Given the 
severity of the current paper shortage, the consequent rise in paper prices, and serious questions about the availability of paper at any price, COM merits serious consideration as an alternative output medium for the widest range of library automation applications.

\section{REFERENCES}

1. Mary L. Fischer, "The Use of COM at the Los Angeles Public Library," The Journal of Micrographics 6:205-10 (May 1973).

2. Doris Bolef, "Computer-Output Microfilm," Special Libraries 65:169-75 (April 1974).

3. Howard A. Sullivan, "Metropolitan Detroit's Network: Wayne State University Library's Serials Automation Project," Medical Library Association Bulletin 56:269-71 (July 1968).

4. See, for example, Auerbach on Computer Output Microfilm (Princeton: Auerbach Publishers, 1972), p.1-10.

5. Hubbard W. Ballou, "Microform Technology," in Carlos Cuadra, ed., Annual Review of Information Science and Technology, v.8 (Washington, D.C.: American Society for Information Science, 1973), p.139.

6. D. R. G. Buckle and Thomas French, "The Application of Microform to Manual and Machine Readable Catalogues," Program 6:187-203 (July 1972).

7. Graham Larkworthy and Cyril Brown, "Library Catalogs on Microfilm," Library Association Record 73:231-32 (Dec. 1971). 